\title{
Health literacy and cardiovascular complications in people with type 2 diabetes
}

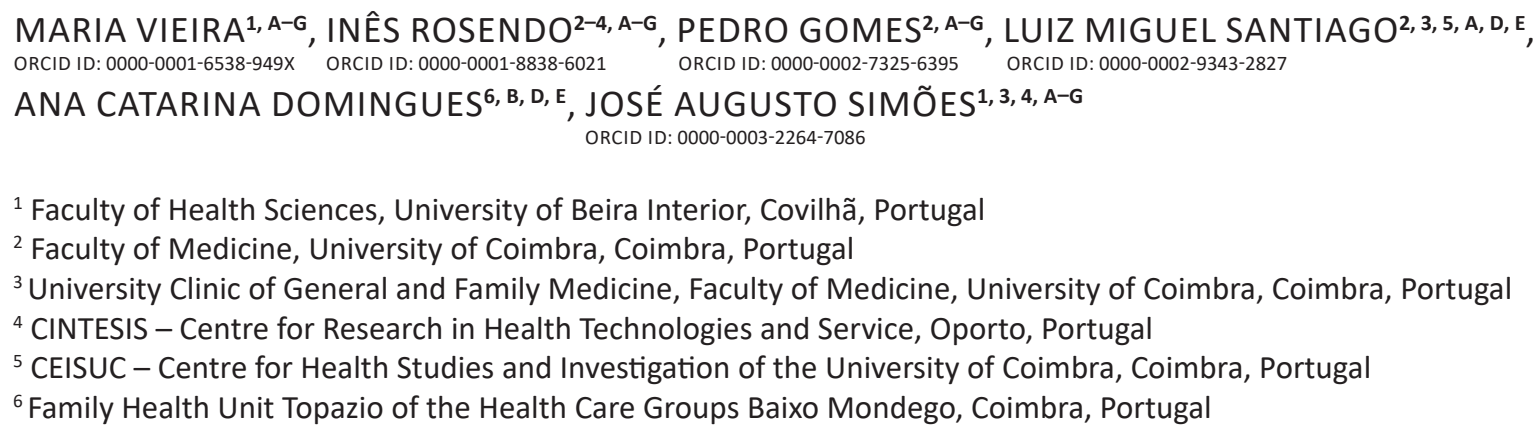

${ }^{1}$ Faculty of Health Sciences, University of Beira Interior, Covilhã, Portugal

${ }^{2}$ Faculty of Medicine, University of Coimbra, Coimbra, Portugal

${ }^{3}$ University Clinic of General and Family Medicine, Faculty of Medicine, University of Coimbra, Coimbra, Portugal

${ }^{4}$ CINTESIS - Centre for Research in Health Technologies and Service, Oporto, Portugal

${ }^{5}$ CEISUC - Centre for Health Studies and Investigation of the University of Coimbra, Coimbra, Portugal

${ }^{6}$ Family Health Unit Topazio of the Health Care Groups Baixo Mondego, Coimbra, Portugal

A - Study Design, B - Data Collection, C - Statistical Analysis, D - Data Interpretation, E - Manuscript Preparation, F - Literature Search, G - Funds Collection

Summary Background. Cardiovascular complications are the main causes of death for type 2 diabetes. Their relationship to socioeconomic factors, such as health literacy, is not well known.

Objectives. To study the relationship between health literacy and cardiovascular complications (acute myocardial infarction, cerebrovascular accident, transient ischemic attack and ischemic heart disease) in type 2 diabetes patients and to understand the relationship of type 2 diabetes mellitus associated cardiovascular disease with empowerment and therapy adherence.

Material and methods. A cross-sectional study with a convenience sample of people with type 2 diabetes in central Portugal. Socio-demographic and clinical characteristics (blood pressure, LDL cholesterol, hemoglobin $\mathrm{A}_{1 c}$ and history of cardiovascular diseases) were collected, and validated scales were applied to assess health literacy, adherence to therapy, empowerment and quality of life. Bivariate inferential analysis between literacy, other variables and cardiovascular diseases, with subsequent Logistic Regression, was performed. Results. A sample of $n=202$, mean age $68.11 \pm 10.19$ years, $n=116(57.4 \%)$ males was studied. Higher health literacy was significantly associated with a lower prevalence of cardiovascular diseases $(p=0.015)$. This relationship was independent of the remaining variables (OR $=0.947 ; 95 \% \mathrm{Cl}: 0.913-0.982 ; p=0.003)$. Significant relationships were demonstrated between cardiovascular disease and quality of life $(p=0.001)$, adherence to total therapy $(p=0.045)$, general diet $(p=0.002)$, physical activity $(p=0.027)$, age $(p=0.004)$ and LDL cholesterol $(p=0.036)$.

Conclusions. The independent relationship between health literacy and cardiovascular disease in people with type 2 diabetes, when confirmed, will indicate that health literacy promotion acts as an important health policy measure to be adopted.

Key words: diabetes mellitus type 2 , health literacy, self care, quality of life, empowerment, treatment adherence and compliance.

Vieira M, Rosendo I, Gomes P, Santiago LM, Domingues AC, Simões JA. Health literacy and cardiovascular complications in people with type 2 diabetes. Fam Med Prim Care Rev 2021; 23(4): 488-493, doi: https://doi.org/10.5114/fmpcr.2021.110367.

\section{Background}

Diabetes mellitus (DM) is an important public health problem causing premature disability and death. These are mainly due to a wide spectrum of complications [1], of which Cardiovascular Disease (CVD) and kidney disease stand out as the main causes of death in diabetic people worldwide [2].

Literacy, "people's ability to make informed daily decisions at home, in the community and in the work-place in the use of health services" is a enablement strategy to increase people's control over their own health, to seek for information and to assume responsibilities" [3]. It is also considered an empowerment strategy, patients so acquiring the necessary influence on the achievement of health out-comes, their behavior, self-caring, critically thinking in autonomy [4]. The mechanisms underlying the relationship between Health Literacy (HL), self-care and clinical outcomes of $\mathrm{DM}$ are poorly understood [5]. Some studies show that low $\mathrm{HL}$ is associated with poor glycemic control [6, 7], while others show that low literacy is associated with poorer knowledge about the disease, as well as with less adherence to self-care, but it is not associated with poor control of glycaemia. Literature is still relatively scarce and ambiguous regarding the relationship between $\mathrm{HL}$ and macrovascular complications in DM $[8,9]$.

Considering the $\mathrm{HL}$ potential for health promotion and disease prevention and the uncertain relationship between $\mathrm{HL}$ and the outcomes of DM, as well as the great impact of CVDs on DM's morbimortality, this study aimed to understand the relationship between $\mathrm{HL}$ and cardiovascular diseases (CVD) [Acute Myocardial Infarction (AMI), Cerebrovascular Accident (CVA), Transient Ischemic Accident (TIA) and Ischemic Heart Disease (IHD)] in people with Type 2 Diabetes Mellitus (T2DM). It also aimed at understanding the relationship between the occurrence of cardiovascular complications and empowerment, adherence to therapy and quality of life in people with T2DM.

\section{Material and methods}

\section{Study design, setting and participants}

A cross-sectional, quasi-randomized study was performed using questionnaires in a representative sample of people with T2DM from four primary care units in central Portugal between 
$07 / 01 / 2018$ to $07 / 17 / 2019$. The selection criteria for primary health care units were being situated in an influence area of both medical schools in central Portugal, receiving medical students for the last two years and being coordinated by a PhD doctor. From the T2DM patients attending specific primary care diabetes consultations in randomized days, those who agreed to participate and signed the informed consent were included in a convenience manner. Exclusion criteria were those not willing to participate, not having the ability to understand the questions and those suffering from mental diseases. Anonymity and confidentiality were guaranteed. Ethics approval was obtained from the Ethics Committee of ARS Centro, and questionnaires author's gave permission to this specific use.

\section{Variables}

\section{The questionnaire included:}

Socio-demographic variables: gender, age, schooling level (number of years completed), living conditions and monthly income (higher, equal or lower than the national minimum wage) were used to determine the Socio-Economic Deprivation Index (SEDI) [10].

T2DM variables: time of disease evolution (years), CVA for stroke, $\mathrm{HbA}_{1 \mathrm{c}}$ level (\%), blood pressure (BP, $\mathrm{mm} \mathrm{Hg}$ ) and $\mathrm{LDL}$ cholesterol $(\mathrm{mg} / \mathrm{dL})$ were recorded by the general practitioners.

HL: a specific scale, known as the Medical Term Recognition Test (METER), was used [11].

Adherence to pharmacological and non-pharmacological therapy: completed using the Diabetes Self-Care Activities Measure (DSCA) [12].

Empowerment: analyzed with the Diabetes Empowerment Scale - Short Form (DES-SF) [13].

Health-related quality of life: recorded using EQ-VAS [14].

\section{Data source/measurement}

The socio-demographic variables were calculated form the questionnaires answers. The Socio-Economic Deprivation Index (SEDI) was calculated giving a score of 1 to each of the following responses: receives less than the minimum wage; attended 4 or less years of schooling and living alone. In the absence of this, a score of 0 was given, so the total score for this index ranged from 0 to 3 . The lower the person's socio-economic index, the higher the SEDI.

As for variables related to T2DM, the "time of disease evolution" and "history of cardiovascular complications" were verified in the respective medical record, as well as the most recent values of $\mathrm{HbA}_{1 c}, \mathrm{BP}$ and $\mathrm{LDL}$ cholesterol.

$\mathrm{HL}$ evaluation was performed using the METER scale (Medical Term Recognition Test), previously validated in Portugal [11]. This scale consists of a list of 40 real health-related words and 30 "non-words" [11]. The participant was asked to read the list and mark only the words he was sure were real. When the patient reported having difficulties with vision, this questionnaire was answered through an interview. In this study, the scale was scored adding the selected real words (Cronbach's $\alpha=0.92$ ). The greater the number of real terms marked, the greater the respondent's HL.

The "Diabetes Self-Care Activities Measure" (DSCA), validated in Portugal (Cronbach's $\alpha$ between 0.36 and 0.68) [12], assesses the adherence to pharmacological and non-pharmacological therapy. The DSCA consists of questions organized by seven dimensions. The first six dimensions cover diabetes care over the last seven days, to which the person responds from 0 to 7 , according to the number of days on which a certain behavior was adopted. The coding was only inverted ( 7 days $=0 ; 0$ days $=7$ ) in dimension two ("Specific Diet"), in which the questions refer to behaviors to be avoided [11]. Regarding "Smoking habits", in this study, we chose to only evaluate question 7.1 "Did you smoke a cigarette, even if only one drag, during the last seven days?" (no $=7$; yes $=0$ ). The analysis of adherence to pharmacological therapy was limited to the question "Over the last seven days, how many days did you actually take your diabetes medications as indicated?". Due to the difficulty the participants showed in understanding what was intended with certain questions in the questionnaire, a decision was made that if the patient asked for it, the interviewers would make the questions, explain them and mark the answer [12].

Empowerment was measured using the "Diabetes Empowerment Scale - Short Form" (DES-SF), validated in Portugal (Cronbach's $\alpha \geq 0.90$ ). This scale consists of eight items that address the patient's psychosocial self-efficacy in relation to T2DM [13]. Answers range from 1 to 5, and the greater the user's empowerment, the higher the score obtained. We opted to apply DES-SF through an interview, given the participants' difficulty in understanding the meaning of the items.

Finally, QdVRS was assessed using the "European Quality of Life - Visual Analogic Scale" (EQ-VAS). This scale is an integral part of the generic instrument for measuring quality of life, "European Quality of Life - 5 Dimensions" (EQ-5D), the use of which is validated in Portugal. The EQ-VAS is described to the patient as a thermometer, whose values range from 0 to 100 , with 0 being the worst health condition imaginable and 100 the best. The user was asked to indicate on this "thermometer" a number that reflected his health status at that time [14].

\section{Bias}

To avoid possible biases in social desirability, the anonymity and confidentiality of the participants in this study was guaranteed, and the questionnaires were applied by researchers identified as medical students and not by the health professionals of each unit. Regarding the variable "cardiovascular complications", for statistical analysis, preference was given to patients' assessments of medical records by the assistant family doctors to avoid possible information and memory bias. The family doctor did not have access to the patients' answers from the questionnaires.

\section{Study size}

Minimal sample size was calculated as of $n=196$, for an error margin of $7 \%$ and a confidence interval of $95 \%$ using ["Raosoft - Sample Size Calculator" (http://www.raosoft.com/ samplesize.html)], considering the population with T2DM in the studied primary health care units of ARS Centro [14, 15]. A sample of $n=202$ was collected.

\section{Statistical methods}

SPSS version 23.0 software (Statistical Package for the Social Sciences) for MacOs (SPSS Inc, Chicago, IL, USA) was used for statistical analysis. Descriptive and inferential statistics were performed after checking the non-normality of the data using the Kolmogorov-Smirnov test $(n \geq 30)$. Thus, the Mann-Whitney test was used to study the relationship between $\mathrm{HL}$ and CVDs and between CVDs and empowerment, adherence to therapy, quality of life and socio-demographic and clinical-laboratory variables. Logistic regression analysis was performed in forward conditional mode, and for the variables with significant relationship to the presence or absence of cardiovascular disease using bivariate analysis. Relative risks and $95 \%$ confidence intervals were calculated, considering $p<0.05$ as significant.

\section{Results}

The calculated sample was $n=196$, and the study sample consisted of 202 persons: 97 (48\%) from UCSP Covilhã [Personalized Health Care Units (PHCU)], 51 (25.2\%) from USF Coimbra Centro [Family Health Unit, (FHU)], 24 (11.9\%) from USF Topázio [FHU] and 30 (14.9\%) from UCSP Mealhada [PHCU]. 
The average age was $68.11 \pm 10.19$ years (minimum 28 and maximum 87 years). Table 1 shows the distribution by gender, age groups and schooling level.

Regarding the schooling level, described by classes in Table 1 , the minimum was 0 , the maximum was 15 years, and the average was $6.10 \pm 3.13$ years.

\begin{tabular}{|c|c|c|c|}
\hline & & $n(\%)$ & $\begin{array}{l}\text { Portuguese popula- } \\
\text { tion with diabetes } \\
(\%)[16,17]\end{array}$ \\
\hline \multirow[t]{2}{*}{ Gender } & male & 116 (57.43) & 58.66 \\
\hline & female & $86(42.57)$ & 41.34 \\
\hline \multirow{5}{*}{$\begin{array}{l}\text { Age groups } \\
\text { (years) }\end{array}$} & $25-34$ & $1(0.50)$ & 2.69 \\
\hline & $35-44$ & $3(1.49)$ & 2.11 \\
\hline & $45-54$ & $16(7.92)$ & 17.67 \\
\hline & $55-64$ & $46(22.77)$ & 38.58 \\
\hline & $\geq 65$ & $136(67.33)$ & 38.94 \\
\hline \multirow{5}{*}{$\begin{array}{l}\text { Schooling } \\
\text { level } \\
\text { (years) }\left(^{*}\right)\end{array}$} & $\leq 4^{\text {th }}$ year & $113(57.36)$ & \multirow[t]{5}{*}{$\mathrm{N} / \mathrm{A}$} \\
\hline & $5^{\text {th }}-8^{\text {th }}$ year & $24(12.18)$ & \\
\hline & $9^{\text {th }}-11^{\text {th }}$ year & $39(19.80)$ & \\
\hline & $12^{\text {th }}$ year & $17(8.63)$ & \\
\hline & $\begin{array}{l}\text { higher educa- } \\
\text { tion }\end{array}$ & $4(2.03)$ & \\
\hline
\end{tabular}

* 5 people did not fill in this information, N/A - not available.

The length of T2DM was of $9.92 \pm 7.81$ years, with a minimum of 0 and maximum of 51 .

Regarding the history of CVD, IHD was the most frequent complication ( $n=28(13.86 \%))$, followed by CVA for stroke $(n=19(9.41 \%))$ and AMI $(n=8(3.96 \%))$. As for TIA, there was only one case. For 7 of the 49 individuals, there were 2 cardiovascular complications, thus the total was 56 (Table 2).

\begin{tabular}{|c|c|c|c|}
\hline \multicolumn{2}{|c|}{ Cardiovascular disease } & $\begin{array}{l}n \text { (total of } \\
\text { cases) }\end{array}$ & $\begin{array}{l}n \text { (total of compli- } \\
\text { cations) (\%) }\end{array}$ \\
\hline \multirow[t]{3}{*}{ IHD } & only IHD & 22 & \multirow[t]{3}{*}{$28(50.00)$} \\
\hline & AVC and IHD & 3 & \\
\hline & AMI and IHD & 3 & \\
\hline \multirow[t]{3}{*}{ CVA } & only CVA & 15 & \multirow[t]{3}{*}{19 (33.93) } \\
\hline & CVA and IHD & 3 & \\
\hline & CVA and AMI & 1 & \\
\hline \multirow[t]{3}{*}{ AMI } & only AMI & 4 & \multirow[t]{3}{*}{$8(14.29)$} \\
\hline & AMI and IHD & 3 & \\
\hline & CVA and AMI & 1 & \\
\hline \multicolumn{2}{|l|}{ TIA } & 1 & $1(1.79)$ \\
\hline \multicolumn{2}{|l|}{ Total } & 49 & $56(100)$ \\
\hline
\end{tabular}

The relative frequency (\%) was calculated with the sum of the total complications $(n=56)$.

IHD - Ischemic Heart Disease, CVA for stroke - Cardiovascular Accident, AMI - Acute Myocardial Infarction, TIA - Transient Ischemic Accident

As for the METER questionnaire, $28.30 \pm 9.13$ real terms were recognized, with a minimum of 0 and a maximum of 40 . Only 52 individuals $(25.74 \%)$ indicated 35 or more real terms out of the existing 40 .
The self-care activity showed greater adherence related to pharmacological therapy. The activity with lowest level of adherence was physical activity (Table 3).

Table 3. Characterization of the answers given in the DSCA measure by the sample under study $(n=202)$

\begin{tabular}{|l|l|l|l|l|}
\hline & Average \pm SD & Min & Max & $n$ (\%) \\
\hline $\begin{array}{l}\text { Adherence to } \\
\text { non-pharmaco- } \\
\text { logical therapy }\end{array}$ & $4.27 \pm 0.98$ & 1.67 & 6.90 & $201(99.50)$ \\
\hline General diet & $4.70 \pm 1.66$ & 0 & 7 & $202(100.00)$ \\
\hline Specific diet & $4.50 \pm 1.28$ & 0 & 7 & $201(99.50)$ \\
\hline Physical activity & $2.44 \pm 2.25$ & 0 & 7 & $202(100.00)$ \\
\hline $\begin{array}{l}\text { Glucose monitor- } \\
\text { ing }\end{array}$ & $3.29 \pm 2.61$ & 0 & 7 & $202(100.00)$ \\
\hline Foot care & $6.36 \pm 1.12$ & 0 & 7 & $202(100.00)$ \\
\hline $\begin{array}{l}\text { Adherence to } \\
\text { pharmacological } \\
\text { therapy }\end{array}$ & $6.96 \pm 0.33$ & 3 & 7 & $202(100.00)$ \\
\hline $\begin{array}{l}\text { Total average } \\
\text { adherence (phar- } \\
\text { macological and } \\
\text { non-pharmaco- } \\
\text { logical) }\end{array}$ & $4.63 \pm 0.80$ & 2.53 & 6.82 & $201(99.50)$ \\
\hline Smoking habits & $5.87 \pm 2.56$ & 0 & 7 & $202(100.00)$ \\
\hline
\end{tabular}

For the "Diabetes Empowerment Scale - Short Form" (DES-SF), the average was $4.03 \pm 0.68$, with a minimum of 2.25 and a maximum of 5, and for the HRQoL, an average of $66.48 \pm 19.19$ was obtained, with a minimum of 6 and a maximum of 100 .

The average $\mathrm{HbA}_{1 \mathrm{c}}$ was $6.98 \pm 1.20$ (minimum $5 \%$ and maximum $12 \%$ for the latest result). The systolic BP was $138.93 \pm 17.37$ $\mathrm{mm} \mathrm{Hg}$ on average, with a minimum of $75 \mathrm{~mm} \mathrm{Hg}$ and a maximum of $176 \mathrm{~mm} \mathrm{Hg}$. The diastolic BP was, on average, $75.02 \pm 11.53$ $\mathrm{mm} \mathrm{Hg}$, with a minimum of $33 \mathrm{~mm} \mathrm{Hg}$ and a maximum of 105 $\mathrm{mm} \mathrm{Hg}$. LDL cholesterol was $94.79 \pm 36.70 \mathrm{mg} / \mathrm{dL}$ on average, with a minimum value of $29.8 \mathrm{mg} / \mathrm{dL}$ and a maximum of $256.0 \mathrm{mg} / \mathrm{dL}$.

Regarding HL (real terms) and cardiovascular complications, a statistically significant relationship was found ( $p=0.015)$, with individuals with a history of cardiovascular complications recognizing fewer real terms than those with no such past. For isolated cardiovascular complications, IHD ( $p=0.007)$, CVA for stroke $(p=0.031)$ and AMI $(p=0.009)$ were equally found. Individuals with CVA and/or IHD presented the same pattern of lesser HL as those with cardiovascular diseases. However, those with AMI recognized a greater number of real terms than those who did not have AMI (Table 4).

Table 4. Characterization of the relationship between the real terms identified in METER and cardiovascular disease

\begin{tabular}{|l|l|l|}
\hline \multicolumn{2}{|l|}{ Average of selected real terms \pm SD } & \multirow{2}{*}{$\boldsymbol{\rho}^{*}$} \\
\hline With CVD & without CVD & \multirow{2}{*}{0.015} \\
\cline { 1 - 2 } $24.16 \pm 11.99$ & $29.63 \pm 7.58$ & \\
\hline With IHD & without IHD & \multirow{2}{*}{0.007} \\
\cline { 1 - 2 } $21.82 \pm 12.55$ & $29.35 \pm 8.02$ & \\
\hline With CVA & without CVA & \multirow{2}{*}{0.031} \\
\cline { 1 - 2 } $23.95 \pm 10.67$ & $28.75 \pm 8.86$ & \\
\hline With AMI & without AMI & \multirow{2}{*}{0.009} \\
\hline $35.25 \pm 3.69$ & $28.02 \pm 9.17$ & \\
\hline With TIA & without TIA & \multirow{2}{*}{0.733} \\
\hline $28.00 \pm 0.00$ & $28.30 \pm 9.15$ & \\
\hline
\end{tabular}

* Mann-Whitney U Test, CVD - Cardiovascular Disease; SD - Standard Deviation. 
According to Table 5, cardiovascular complications were statistically related to worse HRQoL $(p=0.001)$, lower adherence to total therapy $(p=0.045)$, as well as lower adherence to "General diet" ( $p$ $=0.002$ ) and "Physical activity" ( $p=0.027)$ (Table 6). Cardiovascular complications were significantly related to more advanced age ( $p$ $=0.004)$. Total cardiovascular complications were significantly related to LDL cholesterol levels $(p=0.034)$ being smaller.

\begin{tabular}{|c|c|c|c|}
\hline & \multirow{2}{*}{\multicolumn{3}{|c|}{ Total cardiovascular diseases }} \\
\hline & & & \\
\hline & With CVD & Without CVD & \multirow[t]{2}{*}{$p^{*}$} \\
\hline & \multicolumn{2}{|l|}{ Average \pm SD } & \\
\hline $\begin{array}{l}\text { Empowerment } \\
\text { (DES-SF) }\end{array}$ & $4.03 \pm 0.63$ & $4.02 \pm 0.70$ & 0.815 \\
\hline HRQoL (EQ-VAS) & $59.00 \pm 18.79$ & $68.83 \pm 18.77$ & 0.001 \\
\hline $\begin{array}{l}\text { Adherence to non- } \\
\text {-pharmacological } \\
\text { therapy (no. of days } \\
\text { during the last week) }\end{array}$ & $4.07 \pm 0.94$ & $4.02 \pm 0.70$ & 0.083 \\
\hline General diet & $4.14 \pm 1.41$ & $4.88 \pm 1.70$ & 0.002 \\
\hline Physical activity & $1.88 \pm 2.17$ & $2.62 \pm 2.60$ & 0.027 \\
\hline $\begin{array}{l}\text { Adherence to phar- } \\
\text { macological therapy } \\
\text { (no. of days during } \\
\text { the last week) }\end{array}$ & $6.92 \pm 0.57$ & $6.97 \pm 0.20$ & 0.958 \\
\hline $\begin{array}{l}\text { Adhesion to total } \\
\text { therapy (no. of days } \\
\text { during the last week) }\end{array}$ & $4.42 \pm 0.86$ & $4.70 \pm 0.77$ & 0.045 \\
\hline Age (years) & $71.67 \pm 9.72$ & $66.97 \pm 10.11$ & 0.004 \\
\hline $\begin{array}{l}\text { Schooling level } \\
\text { (years) }\end{array}$ & $6.10 \pm 3.45$ & $6.08 \pm 3.04$ & 0.945 \\
\hline SEDI & $4.07 \pm 0.94$ & $4.33 \pm 0.98$ & 0.599 \\
\hline $\begin{array}{l}\text { T2DM evolution time } \\
\text { (years) }\end{array}$ & $11.04 \pm 6.87$ & $9.56 \pm 8.07$ & 0.077 \\
\hline BP systolic (mm Hg) & $142.00 \pm 18.48$ & $138.53 \pm 16.09$ & 0.164 \\
\hline BP diastolic (mm Hg) & $73.98 \pm 10.15$ & $75.37 \pm 11.88$ & 0.249 \\
\hline $\mathrm{LDL}(\mathrm{mg} / \mathrm{dL})$ & $83.49 \pm 29.92$ & $98.36 \pm 37.99$ & 0.036 \\
\hline $\mathrm{HbA}_{1 \mathrm{c}}(\%)$ & $6.76 \pm 1.24$ & $7.05 \pm 1.18$ & 0.054 \\
\hline
\end{tabular}

* Mann-Whitney U Test, CVD - Cardiovascular Diseases, SD - Standard Deviation.

Logistic regression analysis was performed to predict the "presence/absence of total cardiovascular complications". Table 6 shows the variables independently related and significantly contributing to the forecast of the complications under study.

\begin{tabular}{|c|c|c|c|}
\hline & $\begin{array}{l}\text { Relative Risk } \\
\text { (RR) }\end{array}$ & $\mathrm{Cl}_{95 \%}$ & $p$ \\
\hline Constant & 14.645 & - & 0.002 \\
\hline $\mathrm{HL}$ (real terms) & 0.947 & {$[0.913 ; 0.982]$} & 0.003 \\
\hline Cholesterol LDL & 0.987 & [0.976; 0.999] & 0.029 \\
\hline $\begin{array}{l}\text { Average general } \\
\text { diet }\end{array}$ & 0.770 & {$[0.624 ; 0.950]$} & 0.015 \\
\hline \multicolumn{4}{|c|}{$R^{2}$ Nagelkerke $=0.162 ;$ correct global classification $=78.4 \%$} \\
\hline
\end{tabular}

$\mathrm{Cl}$ - Confidence Interval.

They were $\mathrm{HL}(p=0.003)$, LDL cholesterol $(p=0.029)$ and average general diet $(p=0.015)$. For each additional day of ad- herence to a good general diet, the risk of developing cardiovascular complications decreases by about $23 \%$, and for each extra real term recognized on the METER scale, the probability of having cardiovascular complications decreases by $5.3 \%$.

\section{Discussion}

\section{Key results}

The relationship between $\mathrm{HL}$ and total cardiovascular complications proved to be significant, and less literacy was associated with such complications. Conversely, people with AMI showed a superior HL. Adherence to total therapy, general diet, physical activity, age, LDL levels and $H R Q O L$ were significantly related to total CVDs. HL, adherence to general diet and levels of LDL were independently related to total cardiovascular complications.

\section{Limitations of the study}

As a main limitation of this study, METER only evaluates the knowledge of vocabulary, having been validated in Portugal in a young health professional's sample. Thus, we used the continuous levels of the scale, as suggested in the original validation [18]. The questionnaires applied may have suffered a social desirability bias, as they were applied in a health unit by researchers identified as medical students. People with reduced visual acuity were not excluded, which may have skewed some results. Only one person had TIA, so the isolated assessment of this complication is limited. For a cross-sectional, quasi-randomized study, causal inferences are limited. However, the fact that the sample was obtained on pre-specified days by the interviewers allows for some degree of confidence. So no interference in the choice of days or of patients to be questionned by the responsible doctors was achieved.

\section{Interpretation}

In a sample consisting of 202 people with T2DM, 74.3\% had inadequate $\mathrm{HL}$. DM is a complex chronic disease, demanding monitoring and therapeutic management due to its outcomes [7]. These facts could support the statistically significant relationship between $\mathrm{HL}$ and cardiovascular complications $(p=$ $0.015)$, as less literacy is associated with less ability to manage all the complexity inherent to the underlying disease and consequently lead to greater metabolic deregulation and the occurrence of complications. The present study found that this relationship remains statistically significant for each of the cardiovascular complications (IHD, $p=0.007$; CVA for stroke, $p=$ 0.031 and AMI, $p=0.009$ ). The present results are partially in line with those of existing studies reporting significant relationships between HL and CVA for stroke [9] but not with Ischemic Heart Disease (IHD) $[6,7]$. In the present study, there was a significant relationship between HL and IHD. Other studies did not show any relationship between $\mathrm{HL}$ and macrovascular complications of DM $[8,9]$. It should be noted that the non-standardization of $\mathrm{HL}$ scales in the different studies makes it difficult to compare the results.

People with a history of AMI showed higher HL on average. The INTERHEARTH study reported psychosocial stress to be associated with a higher risk of AMI [19]. On the other hand, this result may reflect the limitations of the METER. Although with adequate $\mathrm{HL}$, numeracy and practical application of the information obtained [9] may not be as developed.

Regarding self-care activities, physical activity was the lowest scored item. These results are in line with those already described by other studies [20] and reinforce the importance of promoting healthy lifestyles.

People with a history of cardiovascular complications reported significant lower quality of life $(59.00 \pm 18.79)$ compared to people without complications $(68.83 \pm 18.77)$, as did previous 
studies [21]. Diabetes and its complications imply greater therapeutic and economic burdens and have a negative impact on patients' autonomy and physical and psychosocial well-being.

The level of LDL was, on average, lower in people with CVDs. These values are far from recommended by the most recent guidelines [22]. The fact that LDL is lower in people with cardiovascular complications is probably due to closer monitoring and the awareness of diabetic patients about the importance of therapeutic compliance after the occurrence of cardiovascular events.

Lower HL has been shown to be independently related to the occurrence of total CVDs and thus reinforces the role of $\mathrm{HL}$ as an important non-clinical factor with the potential to reduce the risk of diabetes complications [9]. This potential is supported in the present study, because for each extra real term most recognized on the METER scale, the probability of having cardiovascular complications decreases by about $5.3 \%$. The scarcity/ /inexistence of studies specifically proving the direct relationship between low $\mathrm{HL}$ and the occurrence of CVDs in people with T2DM $[23,24]$ makes comparison difficult, confirming this study's originality. Still, a recent investigation argues that inadequate $\mathrm{HL}$ is an independent predictor of poor glycemic control and the presence of diabetes complications (previous hospitalizations related to DM, neuropathy and retinopathy) [23]. All this data reinforce the need for more research in this area.

The "Average General Diet" also showed a direct relationship with total cardiovascular complications, as it was verified that for each additional day of adherence to a healthy diet, the risk of developing cardiovascular complications decreases by about $23 \%$. Promotion of healthy eating is one of the pillars of diabetes management and plays a significant role in limiting the incidence of associated CVDs [25]. Finally, LDL also showed an independent relationship with total CVDs, reinforcing the importance of its control in reducing cardiovascular risk [26].

\section{Generalizability}

Being a quasi-randomized study, this study has some characteristics to be valued, namely being multicenter in rural and urban areas, with an age and gender distribution close to the one found in 2015 in the Portuguese population with DM [17] and demonstrating the representativeness of the sample studied. Two researchers performed the collection of field data in two different time sets and regions, using the same approved protocol. Thus, the results can be cautiously generalized. According to more recent data, people under the second basic cycle of studies, 6 years, was of $19.9 \%$ in 2020 , and as this study found out they are a main target of concern for increasing $\mathrm{HL}$ [27].

\section{Conclusions}

Low HL was significantly associated with cardiovascular complications in people with T2DM $(p=0.015)$, IHD $(p=0.007)$ and CVA for stroke ( $p=0.031)$. For AMI, $\mathrm{HL}$ is significantly higher $(p=0.009)$. For T2DM associated cardiovascular complications, significant differences with lower $\mathrm{HL}$ were found for $\mathrm{HRQOL}$ ( $p=0.001)$, General diet $(p=0.002)$, Physical activity $(p=0.027)$, Adhesion to total therapy $(p=0.045)$, Age $(p=0.004)$ and for LDL levels $(p=0.036)$.

$\mathrm{HL}$ significantly and independently contributed to the prediction of cardiovascular complications, and for each extra real term recognized on the literacy scale, the risk of developing CVD decreased by about $5.3 \%$.

HL promotion must be considered in the first line of diabetes treatment.

Source of funding: Twhis work was funded from the authors' own resources.

Conflicts of interest: The authors declare no conflicts of interest.

\section{References}

1. World Health Organization. Global report on diabetes [serial online]. Geneva: WHO; 2016 [cited 4.06.2019]. Available from URL: http:// www.who.int/iris/handle/10665/204871.

2. International Diabetes Federation. IDF Diabetes Atlas, 9th ed [serial online]. Brussels: IDF; 2019 [cited 4.06.2019]. Available from URL: http://www.diabetesatlas.org.

3. Pedro AR, Amaral O, Escoval A. Literacia em saúde, dos dados à ação: tradução, validação e aplicação do European Health Literacy Survey em Portugal. Rev Port Saude Publica 2016; 34(3): 259-275, doi: 10.1016/j.rpsp.2016.07.002 (in Portuguese).

4. Łuczyński W, Głowińska-Olszewska B, Bossowski A. Empowerment in the treatment of diabetes and obesity. J Diabetes Res 2016; 2016: 5671492, doi: 10.1155/2016/5671492.

5. Osborn CY, Bains SS, Egede LE. Health literacy, diabetes self-care, and glycemic control in adults with type 2 diabetes. Diabetes Technol Ther 2010; 12(11): 913-919, doi: 10.1089/dia.2010.0058.

6. Schillinger D, Grumbach K, Piette J, et al. Association of health literacy with diabetes outcomes. JAMA 2002; 288(4): 475-482, doi: 10.1001/jama.288.4.475.

7. Saeed H, Saleem Z, Naeem R, et al. Impact of health literacy on diabetes outcomes: a cross-sectional study from Lahore, Pakistan. Public Health 2018; 156: 8-14, doi 10.1016/j.puhe.2017.12.005.

8. Morris NS, MacLean CD, Littenberg B. Literacy and health outcomes: a cross-sectional study in 1002 adults with diabetes. BMC Fam Pract 2006; 7: 49, doi: 10.1186/1471-2296-7-49.

9. Santos RS, Martins OF, Rocha MC, et al. Literacia em Saúde e Adesão à Terapêutica na Diabetes Mellitus. Rev Enf Referência 2014; 11(Suppl.): 21 (in Portuguese).

10. Ribeiro Al, Mayer A, Miranda A, et al. The Portuguese Version of the European Deprivation Index: an instrument to study health inequalities. Acta Med Port 2017; 30(1): 17-25, doi: 10.20344/amp.7387.

11. Paiva D, Silva S, Severo M, et al. Cross-cultural adaptation and validation of the health literacy assessment tool METER in the Portuguese adult population. Patient Educ Couns 2014; 97(2): 269-275, doi: 10.1016/j.pec.2014.07.024.

12. Bastos F, Severo M, Lopes C. Propriedades psicométricas da escala de autocuidado com a diabetes traduzida e adaptada. Acta Med Port 2007; 20(1): 11-20 (in Portuguese).

13. Aveiro MS, Santiago LM, Ferreira PL, et al. Estudo de Fiabilidade da Escala de Capacidade de Controlo da Diabetes: versão breve. Acta Med Port 2015; 28(2): 177-181, doi: 10.20344/amp.5679 (in Portuguese).

14. Ferreira PL, Ferreira LN, Pereira LN. Contributos para a Validação da Versão Portuguesa do EQ-5D. Acta Med Port 2013; 26(6): 664-675 (in Portuguese).

15. Portugal. Ministério da Saúde. Serviço Nacional de Saúde. Bilhete de Identidade dos Cuidados de Saúde Primários [serial online]. Lisboa: Serviço Nacional de Saúde [cited 4.06.2019]. Available from URL: https://bicsp.minsaude.pt/pt/biufs/2/Pages/default.aspx (in Portuguese) 
16. Portugal. Ministério da Saúde. Direção-Geral da Saúde. Programa Nacional para a Diabetes 2017 [serial online]. Lisboa: Direção-Geral da Saúde; 2017 [cited 4.06.2019]. Available from URL: https://comum.rcaap.pt/bitstream/10400.26/22724/1/Programa\%20Nacional\%20para\%20a\%20Diabetes\%202017.pdf (in Portuguese).

17. Observatório Nacional da Diabetes. Diabetes: Factos e Números - O Ano de 2015 - Relatório Anual do Observatório Nacional da Diabetes [serial online]. Lisboa: Sociedade Portuguesa de Diabetologia; 2016 [cited 4.06.2019]. Available from URL: https://www.spd.pt/ images/bolsas/dfn2015.pdf (in Portuguese).

18. Rawson KA, Gunstad J, Hughes J, et al. The METER: A brief, self-administered measure of health literacy. J Gen Intern Med 2010; 25(1): 67-71, doi: 10.1007/s11606-009-1158-7.

19. Rosengren A, Hawken S, Ôunpuu S, et al. Association of psychosocial risk factors with risk of acute myocardial infarction in 11119 cases and 13648 controls from 52 countries (the INTERHEART study): case-control study. Lancet 2004; 364(9438): 953-962, doi: 10.1016/ s0140-6736(04)17019-0.

20. Fernandes FM. Literacia em saúde e adesão à terapêutica na diabetes: estudo exploratório em Portugal [dissertation]. Coimbra: Faculdade de Medicina da Universidade de Coimbra; 2017 (in Portuguese).

21. Fu AZ, Qiu Y, Radican L, et al. Marginal differences in health-related quality of life of diabetic patients with and without macrovascular comorbid conditions in the United States. Qual Life Res 2011; 20(6): 825-832, doi: 10.1007/s11136-010-9819-x.

22. Mach F, Baigent C, Catapano AL, et al. 2019 ESC/EAS Guidelines for the management of dyslipidaemias: lipid modification to reduce cardiovascular risk. Eur Heart J 2020; 41(1): 111-188, doi: 10.1093/eurheartj/ehz455.

23. Anbarasan $S$, Gurtoo A, Srinivaasan M, et al. Level of health literacy among type 2 diabetic persons and its relation to glycemic control. J Assoc Physicians India 2019; 67(4): 59-62.

24. Al Sayah F, Majumdar SR, Williams B, et al. Health literacy and health outcomes in diabetes: a systematic review. J Gen Intern Med 2013; 28(3): 444-452, doi: 10.1007/s11606-012-2241-z.

25. Archundia-Herrera MC, Subhan FB, Chan CB. Dietary patterns and cardiovascular disease risk in people with type 2 diabetes. Curr Obes Rep 2017; 6(4): 405-413, doi: 10.1007/s13679-017-0284-5.

26. Abdul-Ghani M, DeFronzo RA, Del Prato S, et al. Cardiovascular disease and type 2 diabetes: has the dawn of a new era arrived? Diabetes Care 2017; 40(7): 813-820, doi: 10.2337/dc16-2736.

27. PORDATA. População residente com 15 e mais anos de idade por nível de escolaridade completo mais elevado: total e por sexo [cited 7.06.2021]. Available from URL: https://www.pordata.pt/Portugal/Popula\%c3\%a7\%c3\%a3o+residente+com+15+e+mais+anos+total+ e+por+n\%c3\%advel+de+escolaridade+completo+mais+elevado-2101-169766 (in Portuguese).

Tables: 6

Figures: 0

References: 27

Received: 21.04.2021

Reviewed: 11.05 .2021

Accepted: 22.07.2021

Address for correspondence:

José Augusto Simões, MD, PhD, Assoc Prof.

University Clinic of General and Family Medicine

University of Coimbra

Pólo III - Ciências da Saúde, Subunidade 3

Azinhaga de Santa Comba, Celas

3000-548 Coimbra, Portugal

Tel.: +351924 406127

E-mail: jars@fcsaude.ubi.pt, jars@ubi.pt 